\title{
Determinants Factors of Intention to Adopt Big Data Analytics in Malaysian Public Agencies
}

\author{
Noor Zaidi Sahid ${ }^{1}$ (D), Mad Khir Johari Abdullah Sani ${ }^{1}$ (D), Siti Arpah Noordin'1(D), \\ Muhamad Khairulnizam Zaini ${ }^{1}$ iD, Jamiah Baba ${ }^{2}$ iD \\ ${ }^{1}$ Faculty of Information Management, Universiti Teknologi MARA, Puncak Perdana Campus (Malaysia) \\ ${ }^{2}$ Faculty of Education, Universiti Teknologi MARA, Puncak. Alam Campus (Malaysia) \\ zaidisabid@salam.uitm.edu.my,madkhir@yahoo.com,siti@uitm.edu.my, \\ nizam0374@uitm.edu.my,jamia021@uitm.edu.my
}

Received: September 2020

Accepted: December 2020

\section{Abstract:}

Purpose: This research objective was to analyze factors affecting IT practitioners' behavioral intentions in adopting (BDA) using a combination of Initial Trust Model (ITM), Unified Theory Of Acceptance And Use Of Technology (UTAUT) AND Task-Technology Fit (TTF) Model acceptance models.

Design/methodology/approach: Using a cross sectional survey, empirical data were collected. A total of 200 questionnaires were obtained and screened. 14 insufficient answers were subsequently discarded leaving 186 valid structured data review questionnaires. Data was analizad using the Partial Least Square Modeling of Structural Equations due to one of the best software for verifying structured data on structural equations modeling (SEM).

Findings: Our findings show that two key factors determine behavioral intention to adopt BDA in government agencies. Firstly, the assumption that the technology is going to produce great results raises the expectation of performance. TTF was the second determinant factor. Surprisingly, Initial trust, on the other hand, had not been considered to be a key determinant of behavioural intention and was found to be adversely related to the $\mathrm{BDA}$ intention

Research limitations/implications: These findings identify the crucial model, that would be useful to IT officers in public agencies in making investment choices and designing non-adopter-friendly outreach strategies because they have more barriers to acceptance than adopters and lead adopters in the reward ladder.

Practical implications: The findings suggest significant recommendations and consequences for BDA systems practitioners and application developers, which could coincide with the successful implementation of BDA systems. This research gives practitioners an initial way to incorporate and endorse BDA activities in their organization to make the most of the advantages of revolutionary technology, particularly within public agencies.

Originality/value: This study's model is helpful and promotes a theory for further BDA research. By utilizing the model, existing public agencies can know their own BDA capability, centered around activities with specifically

Keywords: big data analytics, public agency, information management, adoption model 


\section{To cite this article:}

Sahid, N.Z., Sani, M.K.J.A, Noordin, S.A., Zaini, M.K., \& Baba, J. (2021). Determinants Factors of Intention to Adopt Big Data Analytics in Malaysian Public Agencies. Journal of Industrial Engineering and Management, 14(2), 269-293. https://doi.org/10.3926/jiem.3334

\section{Introduction and Background of the Study}

\subsection{Introduction}

There have been many attempts of definition for Big Data (BD). More or less BD refers to the large, diverse sets of information that grow at ever-increasing rates. Probably the most popular definition is by Laney (2001) which introduces a model expressing the characteristics of information involved can be expressed in the context of "Volume" of information, the "Velocity" or speed at which it is created and collected, and the "Variety" or scope of the data points being covered. Although Laney did not mention BD explicitly, the model later named as the 3V's was associated to the concept of $\mathrm{BD}$ and use as its definition.

In an analysis of data volume, Desjardins (2019), predicted by 2025, there are expectations for "463 exabytes" of data to be generated globally each day, and 90 percent of these data are unstructured. Alcácera and Cruz-Machado (2019) who studied the growth of the BD trend, mentioned that the managing of large data besides high frequency formats and forms was also closely related. Khan, Yaqoob, Hashem, Inayat, Mahmoud Ali, Alam et al. et al. (2014) continued the concern that within the rapidly rising data medium is unstructured data. This scenario needs Big Data Analytics (BDA) as a tool for faster decision-making processes. BDA can be referred to a complex process of examining $\mathrm{BD}$ to uncover information. In $\mathrm{BDA}$ process, advanced analytics techniques will be used to manipulate $\mathrm{BD}$. BDA reflect the challenges of data that are too vast, unstructured and fast moving to be managed by conventional approaches. Likewise, in its BDA portal, Malaysian Administrative Modernisation and Management Planning Unit (MAMPU, 2016) claims the growth of emerging technologies and generates incentives to enhance industry and government agency efficiency of its services by providing innovative services never before existed.

The BD paradigm offers many advantages and benefits for companies, government and the society. Several scholars have concentrated on BDA adoption in governmental entities (Kim, Choi \& Byun, 2020; Löfgren, \& Webster, 2020; Pencheva, Esteve \& Mikhaylov, 2020; Nantais, 2019 and Abdullah Sani, Zaini, Sahid, Noordin, \& Binti Baba, 2019) and explored the value of BD, especially in private companies (i.e. Hasan, Popp \& Oláh, 2020; Ballantyne \& Stewart, 2019; Mikalef, Pappas, Krogstie \& Giannakos, 2018). Munné (2016) for example listed seven potential benefits of $\mathrm{BD}$, which includes open government and data sharing, citizen sentiment analysis, citizen segmentation and personalization while preserving privacy, economic analysis, tax agencies, smart city and Internet of things (IoT) applications and cyber security. While MAMPU (2016); Kubina, Varmus and Kubinova (2015) asserted BD can improve effeciency in a wide-ranging activities for public sector. OECD (2018) and Wang and Moriarty (2018) believed that BD would cultivate integrity and community wellbeing. For some researcher (such as Kennedy, Moss, Birchall \& Moshonas, 2015), they consider BD would reduce the use of resources in the activities of public organizations.

It is therefore crucial to remain aware of how BD roles are adopted in the public sector and how organizations can gain advantage from BD. While BD and its role in the government agencies were further diligently considered, writers such as Yunus (2018); Pencheva et al. (2020); Munné (2016), argues that the intention to use BD should also help to plan and leverage currently unused data sets in the public sector.

In Malaysia, various agencies are beginning to realize the importance of adopting data analytics in making smart decisions (Paramasivam, 2016). Among them is the provision of infrastructure and info structure to support public data analytics by MAMPU (MAMPU, 2016). A broader perspective has been adopted by Ali, Mohamad \& Sudin (2016) who argued that MAMPU is a body responsible for promoting the modernization and digital transformation of the Malaysian government through BDA. Furthermore, World Bank Malaysia (2017) analyzed related policies 
and strategies, which are also being developed by MAMPU in conducting public data analytics through four pilot applications, namely: "Price Control - Ministry of Domestic Trade, Cooperatives and Consumerism (KPDNKK); Sentiment Analysis - MAMPU; Crime Prevention - Royal Malaysian Police (PDRM) and Infectious Disease Prediction - Ministry of Health Malaysia (MOH)".

\subsection{Research Gap}

MAMPU has conducted pilot applications of BDA involving four government agencies, however the progress of BDA adoption in all government agencies is still low. In fact, the use of BDA needs to be extended to all levels of the ministries to be used as information to formulate effective programs (MAMPU, 2016) based on the "Public Administration Transformation Circulars Bill. 1 of 2017 entitled Implementation of Public Sector Public Data Analysis (DRSA) by the Modernization Unit Administration and Management of Malaysia (MAMPU), Prime Minister's Department". Given the government's serious attention to BD, Raja Mohd Ali, Mohamad and Sudin (2016) are very scarce in terms of public sector preparatory for BD. A research by Paramasivam (2016) showed that $\mathrm{BDA}$ programs foster creativity in public service to simultaneously meet the necessities of the strategic reform programme for a digital government, but only $44 \%$ have started to prepare for a digital strategy and think of their capabilities. By integrating strategies and $\mathrm{BDA}$ adoption factors, it assists the government to implement decisions more effectively (Bahari, 2016) and creates new products and services from the database (Raguseo \& Vitari, 2018), which leads to critical national transformation agenda. Abbasi, Sarker and Chiang (2016) in a BD editorial called for a research exploratory agenda on behavioral factors that influence organization's to use BDA. An organization needs to consider the factors that affect proposed usage of BDA so that they can take effective steps to implement it. Hence, the model developed in this study will reveal what factors influencing BDA adoption should government agencies need to assess.

\section{Literature Review}

\subsection{Big Data and Big Data Analytics}

Industry 4.0 is the fusion of the physical and the virtual world. This digital revolution is marked by technology that takes advantage of $\mathrm{BD}$ and $\mathrm{BDA}$ to nurture decision-making systems. With the exponential speed in creation of data over Internet, organizations find it difficult to store, transfer, segregate, analyzes and stored this data for their best interests. For optimal impact, this huge amount of data must be translated into actionable ideas. In this process, $\mathrm{BD}$ classifies the data collected and draw relevant conclusions that help improve organizations operations.

The "Big Data" term has been used since the 1990s (Madsen \& Stenheim, 2016). Dough Laney in 2001 articulated the now mainstream definition of BD as the 3V's namely Volume, Velocity and Variety. Then the other two Veracity and Value got added to the model to make it 5V's model. According to 5V's model by Bello-Orgaz, Jung and Camacho (2016), BD can be described based on its characteristics :

$\begin{array}{ll}\text { Volume } & \text { - the size of BD. Data that can be considered BD or not is based on the volume. } \\ \text { Velocity } & \text { - the speed at which the data is getting accumulated } \\ \text { Variety } & \text { - refers to structured, semi structured and unstructured data } \\ \text { Veracity } & \text { - the assurance of quality/integrity/credibility/accuracy of the data } \\ \text { Value } & \text { - refers to how useful the data is in decision making. The value need to extract using proper BDA. }\end{array}$

These paradigm is the most important elements to extract valuable information from data which also known as Big Data Analytics. The term Big Data Analytics (BDA) covers advanced analytical techniques and technologies that operate on BD to obtain enhanced insights and improve the decision making process (Malaka \& Brown, 2015). Appropriate data processing and strategy to use BD technologies could expose new strategic knowledge and facilitate in responding to emerging opportunities and challenges in a timely manner (Chen., Chen, $\mathrm{Du}, \mathrm{Li}, \mathrm{Lu}$, Zhao, S. et al., 2013) and facilitates an informed decision-making culture (Wang \& Jones, 2017). In its systematic analysis, Khan et al. (2014) found various kinds of organized and non-organized social media data including blogs, Facebook, Twitter and others. These have contributed to the creation and growth of mass media, distributed, limitless and invaluable (volume, range, pace, value) data amounting to terabytes and petabytes. The BD trend has 
stimulated new technologies and open space and private companies to enhance service quality for the society, and to boost corporate efficiency and government performance (MAMPU, 2016). This position is supported by Domingue., Lasierra, Fensel, van Kasteren, Strohbach and Thalhammer (2016) who argues that the data are emerging trend was strongly linked to the output of data in broad and high frequency formats and forms. It has the capacity to encourage innovative technologies and to open up space for business and government bodies to increase the quality of services that they have never considered possible.

Some surveys have been performed to evaluate the situation of the BD model in organizations. These are some of the BD Surveys, which the Capgemini Consulting, 226 global leaders in Europe, North America and Asia Pacific conducted in 2014. The results showed that most $(35 \%)$ of the surveyed participants were already in a partial manufacturing stage where predictive data technology was already incorporated into their business activities while some are in the idea preparation stage (29\%), some have not yet been implemented (24\%), and only $13 \%$ are established (Capgemini Consulting, 2014).

BDA provides strategies and technologies for gathering, storing, transferring, analyzing and displaying vast volumes of structured and unstructured data (Erevelles, Fukawa \& Swayne, 2016). Others (see Elragal \& Klischewski, 2017; MAMPU, 2020; Al-Shiakhli, 2019) emphasized the BDA as the use of profound learning techniques on large datasets, including data collection, analysis, prescriptive modelling, etc., as modern business intelligence practice. Some other way of thinking of BDA is the method of analyzing data sets so as, with the help of advanced systems and software, to draw conclusions about the information they produce (Stedman, 2017). Data science methods and technologies in the industrial sectors are commonly used to allow organizations to make informed decisions and science experts and researchers to validate or falsify science models, theories and hypotheses.

\subsection{Assessing the Public Sector to Adopt Big Data Analytics}

Longo and McNutt (2018) discussed how BD could change the public agencies data analytics (DA) strategy. DA is the evaluation of solutions for public agencies issues. The traditional data analysis is characterized by conventional quantitative analysis methods used in the 70s and 80s (Longo \& McNutt, 2018). However, BD, supported by the modern-day technology, can enhance public agencies. Günther, Rezazade, Huysman and Feldberg (2017) and MAMPU (2017) concluded by highlighting some of the issues associated with adopting BD, one notably that government has to build enough capacity for an appropriate application data analytics in government bodies. This can be accomplished by providing training to the public employees (OECD, 2018). Similarly, Schintler and Kulkarni (2014) found other potentials or threats in the public service leveraging BD. The benefit includes provision of useful information, and detailed, precise and prompt decision-making data (Pencheva et al., 2020; World Bank Malaysia, 2018; MAMPU, 2017). However, using BD comes with some notable challenges. The fact that BD are usually skewed, too complex (Sivarajah, Kamal \& Weerakkody, 2017), and tend to be missing some relevant information; are in brevity, BD tend to be biased in some cases (McFarland \& McFarland, 2015). A set of BD might have lost its contextual value when they are being processed, reshuffled, repurposed and reinterpreted going through the phase of being supplied to the end users (Schintler \& Kulkarni, 2014).

As far as the theoretical and practical data usage of government departments, it provides a solid foundation for BDA (Sivarajah et al., 2017). BDA tools must therefore be incorporated into the study of public agencies. One of the challenges identified by Giest (2017) and Ingrams (2019) is limited institutional support for BD management and capacity within the government. As highlighted by MAMPU (2017), when the government has low level of analytical capacity, they would have to source for additional stakeholders with the right skill sets. Furthermore, UNESCO (2017) opined that the issue of capacity can be solved by training government workers in data analytics or simplifying the ambiguities involved in analyzing BD for policy decision making. Walker and Brown (2019) agreed that using BD in policymaking should be at the problem identification stage, where data serves as an evidence to gauge the severity of a social problem. BD should also serve as the basis for policy makers in setting their priorities; should be considered at the root cause analysis stage for social problems (Sivarajah et al., 2017) and factors influencing intent to adopt need to be explored systematically as done by different scholars, as condensed in Table 1. 


\begin{tabular}{|c|c|c|c|}
\hline Authors & Method & Object of Study & Findings (Influencing Factors) \\
\hline $\begin{array}{l}\text { Shahbaz, Gao, Zhai, } \\
\text { Shahzad and } \mathrm{Hu}(2019)\end{array}$ & Survey & Health Institutions & Task-Technology Adoption Paradigm \\
\hline $\begin{array}{l}\text { Maroufkhani, Wan Ismail } \\
\text { and Ghobakhloo (2020) }\end{array}$ & Survey & $\begin{array}{l}\text { Small- and medium-sized } \\
\text { enterprises (SMEs) }\end{array}$ & $\begin{array}{l}\text { Technology and organization are } \\
\text { determinants for BDA adoption }\end{array}$ \\
\hline Schüll and Maslan (2018) & $\begin{array}{l}\text { Online } \\
\text { survey }\end{array}$ & $\begin{array}{l}\text { German companies in different } \\
\text { sectors }\end{array}$ & $\begin{array}{l}\text { TOE framework as BDA adoption } \\
\text { enablers }\end{array}$ \\
\hline $\begin{array}{l}\text { Cabrera-Sánchez, and } \\
\text { Villarejo-Ramos (2019) }\end{array}$ & Survey & Companies in different sectors & $\begin{array}{l}\text { Behavioural intent to use BDA in } \\
\text { companies }\end{array}$ \\
\hline $\begin{array}{l}\text { Behl, Dutta, Lessmann, } \\
\text { Dwivedi and Kar, (2019). }\end{array}$ & Case study & E-commerce company & 11 enablers of adoption of BDA tools \\
\hline Sam and Chatwin (2019). & Survey & Organization in different sectors & TOE readiness to adopt $\mathrm{BD}$ \\
\hline Walker and Brown (2019) & Case study & Telecommunication organizations & TOE and BDA adoption model \\
\hline Hiruni and Piyavi (2020) & Survey & Apparel sector & $\begin{array}{l}\text { TOE and TAM model influences user } \\
\text { atitude to adopt BDA }\end{array}$ \\
\hline
\end{tabular}

Table 1. Summary of Relevant Research on Factors Influencing Intent to Adopt BDA

\subsection{Existing Models}

The main influences in this work were the Initial Trust Model (ITM) (McKnight \& Chervany, 2006) the Unified Theory of Acceptance and Use of Technology (UTAUT) (Venkatesh, Morris, Davis \& Davis, 2003), as well as the Task Technology Fit (TTF) (Goodhue \& Thompson, 1995) model, which were used in predicting the behavioral intentions towards BDA (Shahbaz, et al., 2019).

\subsubsection{Initial Trust Model (ITM)}

A person's desire to meet his/her needs without having previous experience or accuracy and relevant information implies the meaning of initial trust (Kim \& Prabhakar, 2004 and Gao \& Waechter, 2017). The simple, scalable, and expected advantages, such as service quality, are linked to initial confidence creation (Koufaris \& Hampton-Sosa, 2004). When users have little to no history in accepting new technologies, the initial trust plays a significant role (Shahbaz et al., 2019). Consequently, these users seek insight which ensures reliable data and analysis (KPMG, 2016). The position of initial e-commerce trust is correlated with areas such as online shopping (Jibril, Kwarteng, Appiah-Nimo, 2019) and mobile banking services (Lin, Wang \& Hung, 2020) that have been thoroughly researched in this field. Mahfuz, Khanam and Hu (2019) employed the ITM to create a model that describes mobile banking adoption to customers in Bangladesh.

Researchers have highlighted diverse initial trusts influence factors that could be described in two major categories. The first category relates to individual personality traits such as the propensity to trust that represents the individual's natural inner potential. In the preceding analysis, a good predictor for initial trust is trust propensity (Kaabachi, Mrad \& O'Leary, 2019). The personal inclination directly affects initial trust, which is supported by Heidari, Moosakhani, Alborzi, Divandari and Radfar's (2018) findings. The second category is structural assurance. The trust is focused on the favorable outcomes of other parties' future actions (Zhou, 2013) and on their ability to be vulnerable. Trust typically consists of three convictions: ability, integrity and generosity (Zhou, 2013). Confidentiality has been shown to have profound consequences for the use by users in a range of services, including Online Health Consultation Services (Gong, Han, Li, Yu \& Reinhardt, 2019), online banking (Kaabachi et al. 2019), social networking (Naqvi, Jiang, Miao \& Naqvi, 2020), and public e-services (Alabdallat, 2020).

As data science emerges in the last couple of years, trust in BDA area becomes more important. For example, Shahbaz et al. (2019) have demonstrated Positive influence of the trust and strength in the information system on BDA conduct intentions. The trust in technology, reviewed by Madhlangobe (2018), has a positive effect on intended use of BDA while Debussche, Cesar and Moortel (2019) stress "the important aspect of" confidence "in the context of $\mathrm{BD}$ is confidence because stakeholders believe in honesty in the process of gathering, treating and 
analyzing BD." It is from an analytical point of view Woolley (2019) that analyses comply with ethical standards and meet the information requirements and maintains public trust in the mechanism of decision taking.

\subsubsection{Unified Theory of Acceptance and Use of Technology (UTAUT)}

Cao \& Niu (2019) conducted a survey, which explains the determinant factors affecting users to take Alipay as one of payment platforms in China. This research includes the theory and UTAUT on context awareness. Context, ubiquity, social impact, performance expectation, expected effort, perceived risk and the Alipay user acceptance are all constructs. Efficiency and effort expectancy act as a mediation construct for Alipay app acceptance from context to ubiquity. The context has a positive influence on customers' acceptance through mediation effort and performance expectations as a result of path analysis, while ubiquity has influence too.

Yang, Feng and MacLeod (2019) also integrated UTAUT and Connected Classroom Climate (CCC) in their research. The findings show that actions, social impact and CCC substantially influence the Cloud classroom adoption. In their field of research, Kurt and Tingöy (2017) aimed at investigating to what degree students accept and use virtual or online school learning environments. The findings show that behavioral intent of the performance expectancy variables is significantly affected.

Ngampornchai and Adams (2016) carry out a study aimed at finding out how many Thai students can accept elearning and how they respond to e-learning. The research variables were adapted from the UTAUT and Moore and Benbasat's (1991) models. The findings indicate a significant relationship between achievement and effort expectancy. Social influence also has a positive relationship. This is evidenced by the students' statement that their parents are happy to have their child enrolled in an online course. In addition, e-learning acceptability is often connected to the year of school. Senior students tend to be more responsive to e-learning, even if only a few of them take online classes. The relevance of this study is also its use of the UTAUT model, but there is still a shortcoming as it included only one item to measure performance expectancy influence variables.

\subsubsection{Task-Technology Fit (TTF) Model}

A technology which in TTF enables a person to accomplish his or her tasks (Spies, Grobbelaar \& Botha, 2020) is defined and crucially influenced by the interplay between task characteristics and technology functionality (D'Ambra, Wilson \& Akter, 2013). Data quality, data location, access authorisations, data compatibility, easy use / training, timeless manufacturing, system reliability, user information system relationships are the typical dimensions considered when measuring fit as described by Goodhue and Thompson (1995). Characteristics of the task and technology decide TTF, which contributes to the information system being adopted and used (Goodhue \& Thompson, 1995). Several researchers have employed the TTF model. Said (2015) used TTF to examine the performance effect determinants of knowledge management system. Liebenberg et al. (2018) applied the updated TTF model to analyze the variables impacting the insurance industry adoption of mobile commerce (Lee, Cheng \& Cheng, 2007). Klopping and McKinney (2004) used a hybrid approach that merged TTF and technology acceptance models to test e-commerce adoption.

Effective information system implementation fits the definition of the purpose for which the innovation is used and on an acceptable linkage between technology and its objective. Goodhue and Thompson (1995) explained TTF decomposition explores the user's information system specifications, which ultimately have an effect on individual results. The TTF model reflects a significant positive impact for smartphones in the digital library environment of tasks and technologies as revealed by Vongjaturapat's (2018) study. Technology means the integration of different supporting activities (i.e. computers and applications) for these tasks. Previous research by Bibri \& Krogstie, (2017) defined specific role dimensions (e.g. storage, data aggregation, analysis, data management and surveillance) applied to a variety of technological aspects that met the needs of individuals in BDA technology. Task and technologies also have a huge effect on the TTF capacity to predict success of users hailing from digital textbook service study (Rai \& Selnes, 2019). If the individual demands for success were not met; creative information technology and program would be inopportune (Zhou, Lu \& Wang, 2010). Recognizing the BDA program TFF is also essential, as it contributes to public organizations implementing the program 
In recent research, TTF has analyzed the efficiency of the user's technology and group-level decision-making process to assess the performance of various organizational settings of the information system (i.e., massive Open Online courses [MOOCs] (Heidari et al., 2018); BDA and the digital library (Omotayo \& Haliru, 2020). Accordingly, we conclude that the successful implementation of BDA by public agencies depends substantially on balancing technology with the user role requirements, which previous researchers have not examined. In their survey, Rai and Selnes (2019) conceptualized TTF and even the integration of technology with a number of related tasks that help in achieving the development goal in an organization.

\section{Hypothesis and Research Model}

The conceptual model for this study was chosen from Oliveira, Faria, Thomas and Popovičs (2014) analysis, which used the composite theoretical paradigm of the initial confidence paradigm, the TTF model, and a coherent theory of UTAUT to forecast acceptability of mobile banking among final consumers (Oliveira et al. 2014).

\subsection{Designing the Conceptual Model}

As for every emerging technology, BDA performs a significant position in longevity of innovation and efficiency (Rialti, Zollo, Ferraris \& Alon, 2019). The survey instrument and analysis model are developed to test the relation between the concepts of the ITM model, the TTF model, and the UTAUT. Since BDA facilitates the protecting of government agencies' transaction data, IT professionals' confidence in BDA technology is a crucial factor in adopting this technology. The confidence is a core topic in BDA, as demonstrated by Schneider, Handali and vom Brocke (2018). It can help to improve confidence in BDA by explaining "blackbox" models, demonstrated models' transferability, and structural rigidity in terms of data adjustments to quality or contents. The TTF and initial assurance models are the basis in this study to assess BDA system adoption in combination with the original trusted model to analyze the IT professionals' attitude in modifying the trusted model.

BDA and intelligent contracts are viewed as useful tools to government agencies (Mithas, Tafti, Bardhan, \& Goh, 2012). The survey methodology and analysis model have been developed in determining connections respectively the principles of the confidence model, the task-application model and the coherent system acceptability and usage principle (UTAUT). Since BDA is responsible for protecting transaction details and the intelligent contract is used for the execution of public services transactions, the user's confidence in the BDA technology is a key element in the acceptance of such technologies in government agencies (MAMPU, 2016). Given that BDA affects the security paradigm of the users, this transition involves a shift in the mindset of users, as public agencies were historically responsible for building trust; now the trust is cryptographic due to the existence of BDA and the elimination of intermediaries (OECD, 2018). Of the same cause, the model of the study consists of a task-technology match model, and an original confidential model under which the TTF model and ITM were used to measure the effectiveness of BDA technology as a financial method to analyze consumer behaviour towards modifying the confidential trend.

The UTAUT system plays a minor role in the study paradigm because of the presumed existence of BDA technology. The calculation of the UTAUT platform adoption rate is not an effective technique. The purpose to perform is one of the acceptance variables of this equation, selected as the dependent variable. Of the four UTAUT principles (Venkatesh et al., 2003), only a performance expectation concept was used to test the hypothesis. The assumption of $\mathrm{BDA}$ as a measure of the profitability of the enterprise contributed to improved corporate success. The success appraisal component analyzed employee efficiency, operational performance, and customer satisfaction (Vitari \& Raguseo, 2019). Perceptions of effort and social impact have disrupted the study because the respondents have no realistic experience of this application. Moreover, the TTF theory asserts that the system will be used by the user if the technical features meet task requirements, based on Goodhue and Thompson's (1995) theory. It is also possible to adopt this technology if the user finds technology as useful, simple and innovative, but if it does not meet the requirements, its required tasks and does not improve job performance, it may not be adopted as discovered by Zhuang, Wu, Chen and Pan (2017). The user should therefore not only have to believe that such innovation is efficient and helpful but also that the technology features will conform to the necessary tasks. 
Among the four UTAUT principles (Venkatesh et al., 2003) the theory has been verified only through a principle of performance expectation. Prior work shows that anticipation of resut and its performance outcomes are the determining factors of behavioral intent. For BDA, this could lead people to believe for employees to use conventional working practices when they trust that BDA technologies and applications will not help them operate better or perform more efficiently. Expectations of commitment and social impact have disrupted the study because the respondents have no realistic experience of this application. It has also been observed that promoting circumstances directly influences the adoption of this definition (Venkatesh et al., 2003). The study dimension of the model was therefore not used.

\section{Hypothesis 1}

Structural assurance provides assurance that the BDA could be carried out in a protected and secure way that protects users from data loss or exposure to privacy by maintaining protective and technological structures [3]. Trust is related to structural assurance as found from McCole, Ramsey, Kincaid, Fang and Li (2019) investigate in the situation of true e-service (online betting). Higher levels of systemic assurance will help BDA users conquer fear of revealing sensitive data broadly and raise their level of confidence in such data. The summaries of the International Telecommunication Union (ITU) (2018) reports on "BD, machine learning, consumer protection and privacy", that the large quantity of data held and transmitted by BD players creates risks of violation of data security, and thus of privacy and trust for consumers. Right to privacy can be protected in different ways by using technologies to enhance privacy (PETs).

\section{H1. Structural assurances in the BDA have a positive effect on the initial trust.}

\section{Hypothesis 2}

Through previous interpersonal trust study, the tendency to trust has indicated faith and trust through actions. Alarcon, Lyons and Christensen (2016) have used a revamped version of the dilemma duties of the inmate to discuss the relationship of loyalty and trust both in common and new ways. The confidence tendency was calculated using a revised Mayer and Davis' (1999) confidence scale and perceived trustworthiness Fiduciary scale edition. Heidari et al. (2018) found the the initial trust significantly influced by personal propensity to trust among innovators familiar with the blockchain technology accounting for 222 subjects. Researchers have highlighted diverse initial trusts influence factors that could be described in two major categories. The first category relates to individual personality traits such as the propensity to trust that represents the individual's natural inner potential. In the preceding analysis, a good predictor for initial trust is trust propensity (Kaabachi et al., 2019). The personal inclination directly affects initial trust, which is supported by Heidari et al. (2018) findings. The second category is structural assurance.

\section{H2. The personal propensity to trust in the BDA technology has a positive effect on the initial trust.}

\section{Hypothesis 3}

The trust degree begins at zero before an individual undertakes interactions and relationships (Lewicki \& Bunker, 1996). Falahat, Lee, Foo and Chia (2019) argued that individuals are in trust to decide if online exploration or transaction is necessary. Initial trust is the initial step when there is a lack of immediate information, credibility and knowledge of BDA (Sbaffi \& Rowley, 2017 and Falahat et al., 2019). Initial trust is the introductory stage. Sbaffi and Rowley (2017) also proposed an initial trust model that individuals will use to decide whether to explore or deal online especially with BD. Initial trust and perceived utility as values, according to the principle of reasoned action (TRA), can influence behavioral motives (Yu \& Lee, 2019). Initial trust may also help to mitigate perceived vulnerability and danger and encourage deliberate use. It was observed that perceived utility was a major factor impacting initial usage and persistent usage (Venkatesh \& Davis, 2000). Many studies have documented the influence of initial trust in behavioral motives and their presumed utility (Okello \& Gilson, 2015) and Talwar et al., 2020a). Possible IT professionals find better decisions on analytics or technology that could dictate whether or not they may use BDA in the near term. Initial trust is willingness to rely on things, which makes individuals believe the risks and uncertainties of trading (Smithson, 2018). In order to resolve risk perceptions of IT professionals and 
persuade IT professionals to negotiate with them, government agencies therefore should have appropriate trust in this first level, which is notably crucial for the performance of BDA.

\section{H3. Initial trust has a positive impact on the user's intention in accepting the BDA technology in government agencies.}

\section{Hypothesis 4}

Technologies are characterized as "devices that people use to accomplish their tasks." "Software applies to computing programs in the sense of Information System (hardware, Technology, software and support services to users (trainings, help lines, etc.)) is provided to enable users to carry out their tasks" (Goodhue \& Thompson, 1995: page 216). The model of TTF emphasized the significant of adjusting to the specifications imposed by individual needs the capabilities and qualities of technology (Vongjaturapat, 2018) and consistently Schindler, Burkholder, Morad and Marsh (2017) critical review of the literature when they found the characteristics of technology (accessibility, response time) can influence technology use and user preferences. Goodhue and Thompson (1995) proposed that user reviews would not be arbitrary, but rather represent the realistic characteristics of the relevant system and facilities. Goodhue and Thompson's (1995) interpretation of task-technology disregards the interdependence of tasks.

This study has therefore customized the TTF to analyze Compatibility between the roles of IT practicers and BDA, as the model would be used to assess the use of BDA as clarified from a task perspective. It is expected that in the situation that they perform their tasks with minimum costs, optimum productivity and performance, the IT practitioners are more favorable to use BDA (Mikalef, Boura, Lekakos \& Krogstie, 2019). The adoption model for Task-Technology Fit (TTF) indicates that the customer should approve a new system when it is effective enough to perform routine tasks (O'Connor, Andreev \& O'Reilly, 2020). Acceptance of the current information structure thus depends entirely on the everyday routine activities of the staff in the organization. The task features and technology features decide the task-technological fit, which contributes to the information system being adopted and used (Goodhue \& Thompson, 1995). TTF model was employed by several researchers. Wang and Lin (2019) found TTF is significantly influenced by BDA's technology features in mobile cloud healthcare. Likewise, as evidenced by Shahbaz et al. (2019) technology features have major effects on TTF 's ability to provide BDA in healthcare.

\section{H4. The technological features of the BDA bave a positive effect on the task-technology fit.}

\section{Hypothesis 5}

TTF into the degree of technology defined by Goodhue and Thompson (1995). Whether or not BDA technology will help users to carry out their job, the task-to-tech fitness needs to be observed at the time of application (Laugesen \& Hassanein, 2017; Wu \& Chen, 2017; Tam \& Oliveira, 2016). The TTF into this study: how users utilize the BDA features to carry out government service tasks. BDA-related task features are generated on a very large scale and many multinationals process and analyze them so that insights can be found, and organizations can be improved (Lehrer, Wieneke, Vom Brocke, Jung \& Seidel, 2018). The task features have a positive impact on the TTF from different studies as confirmed by (eg. in BDA setting (Wang \& Lin, 2019 and Shahbaz et al. 2019); smartphones setting (Vongjaturapat, 2018 and Bere, 2018); cloud computing setting (Khidzir, Ghani \& Guan, 2017 and Yoo, \& Kim, 2019) blockchain setting (Heidari et al., 2018). An important task feature of BDA is advanced analytics with complex applications, such as predictive modelling, statistical algorithms and high-performance analysis systems. This study presents the preceding assumption:

\section{H5. The task. features of BDA have a positive impact on the task-technology fit.}

\section{Hypothesis 6}

The efficient use of an IT system depends on the role to be performed and whether the job and the systems are sufficient. As explained in Goodhue and Thompson (1995), TTF decomposition examines the information system requirements of the user, which ultimately affects each individual's performance. The integration of a range of support activities to fulfil these tasks is the technology (i.e. computers, applications, etc.). Latif, Tunio, Pathan, Jianqiu, Ximei and Sadozai's (2018) finding contribute to a variety of technological criteria that meet the individual's 
needs (e.g. non-routines, coexistence, data access, and quantitative data analytics). TTF capability is derived from Task and technology to predict users' performance from various perspectives (Rai \& Selnes, 2019). Innovative software and system technology would be unsuccessful if the performance criteria for a given task were not met (Shahbaz et al. 2019). Moreover, Shahbaz et al. (2019) discovered that the TTF corresponds significantly to improving the behavioral intentions of the BDA system in the healthcare industry. Interestingly, TTF proves to be significantly associated to the adoption of cloud computing in Khidzir et al., 2017 research. It is also essential to achieve the BDA program task-technology match because it helps government agencies implement the appropriate program and strategy.

H6. The task-technology fit has a positive effect on users' behavioral intent in adopting BDA in government agencies.

\section{Hypothesis 7}

Performance expectancy sheds light on understanding the importance of the emerging technologies and is one of the most prominent behavioral intentions. The estimation of results in the UTAUT tests a person's confidence that the system is useful and advantageous to the user (Venkatesh et al. 2003). Oliveira et al. (2014) consider the predicted performance in the UTAUT as the expected performance in the technology adoption model and consideration it as a critical part of the proposal to the technology acceptor (Oliveira et al., 2014). The statistically direct relationship in the context of performance expectancy and behaviour BDA intention is confirmed by several studies (Cabrera-Sánchez \& Villarejo-Ramos, 2019; Chao, 2019; Queiroz, \& Farias, 2019).

H7. The performance expectancy will positively affect the user's behavioral intent in accepting the BDA in government agencies.

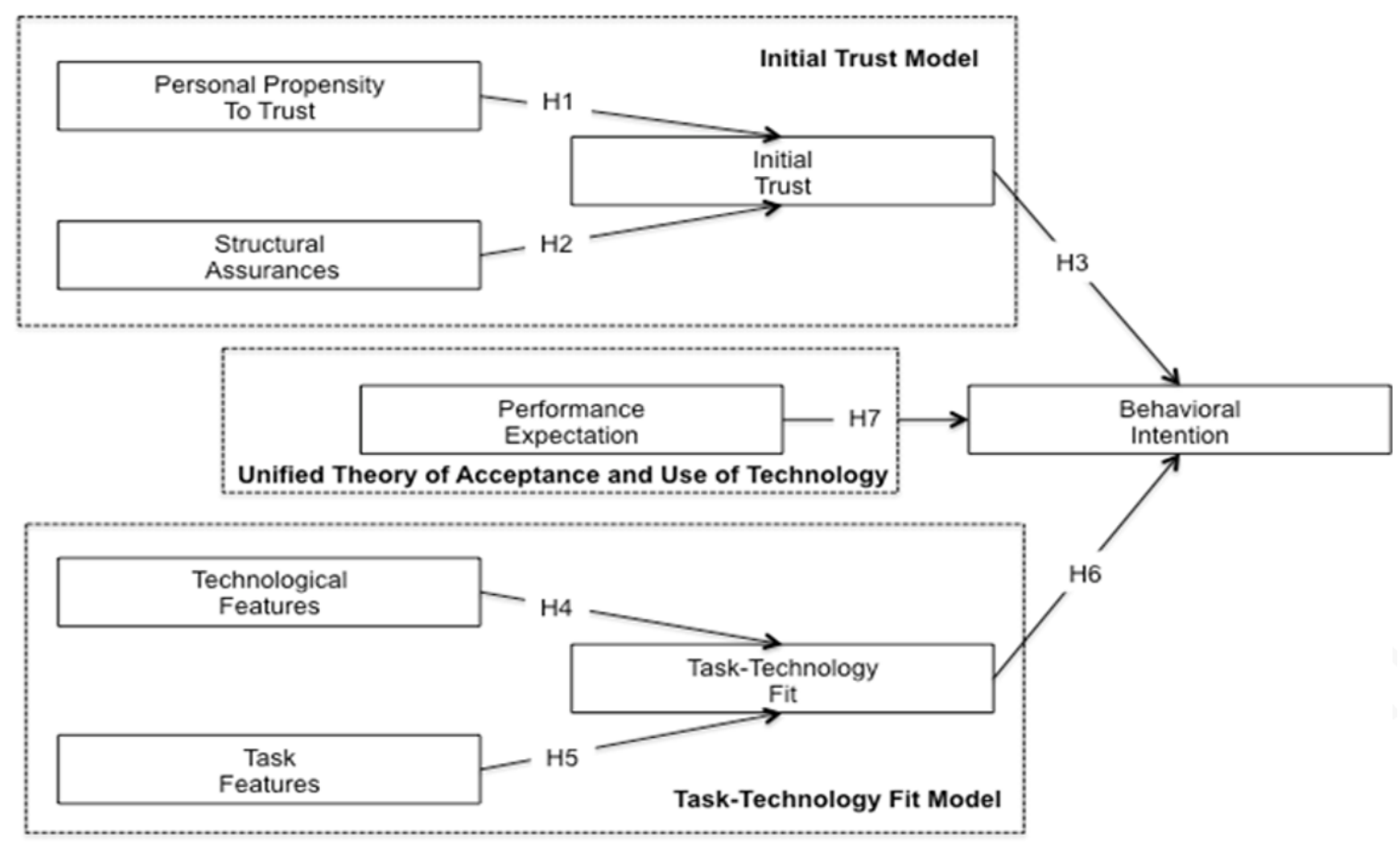

Figure 1. Research Framework

\subsection{Malaysian Public Agencies as the Study Population}

Malaysia has prioritized data science as a national plan and is well equipped to leap over other countries by incorporating it into a program that leads to more evidence-driven decision-making organizations (MAMPU, 2016). In this regard, a pilot project aimed at improving public sector IT climate landscape was declared by the government of Malaysia to introduce the Analitis Data Raya Sektor Awam (ADRSA) involving multiple ministries (Helmi, 2018). This program encourages creativity in government services while meeting the essential needs of the national digital government modernization agenda. Incorporating data from various sources helps the government 
to implement decisions more efficiently, creates new database products and services, shares information and results, leading to a critical national transformation agenda. The Ministry of Communications and Multimedia (MCMC) has led the implementation of BDA in Malaysia, in collaboration with MAMPU and Malaysia Development Corporation (MDeC), and established BDA for Malaysia (MAMPU, 2016).

The Microsoft study in the 2016 Asia Data Culture survey revealed that $85 \%$ of policymakers in Malaysia believed it is essential for business to make use of data, but only $44 \%$ have started to prepare for a digital strategy. The Microsoft survey comprises 940 small and large business leaders in 12 Asian markets. 45 of them came from Malaysia alone (Paramasivam, 2016). Most of those from Malaysia agreed with the cultural advantages of BDA, but there are obstacles to be overcome. Using BDA, Malaysia Airport Berhad, coupled with the right communication strategies, found the total number of positive items in customer feedback management was calculated at $72 \mathrm{~K}$ compared to the negative $27 \mathrm{~K}$ items, which is significant in providing better passenger experience through new customer engagement channels such as social media (The Multimedia Development Corporation (MdeC), 2016). Furthermore, Lagisatu.com asserts that the benefit of BDA adoption is the delivery of timely insights from the vast amount of data. Similarly, Paramasivam (2016) found approximately $88 \%$ of Malaysian businesses confidently reported BDA will determine their success in the industry. Clearly, the industry has begun to understand the importance of IT graduates and skilled manpower (talent capabilities) in the field of data analysis. MAMPU (2016) claimed if organizations understand and collect the data in connection with their trade or business, they can analyze and gain value significantly from it as well as are able to estimate trends and to anticipate market growth.

\section{Research Design}

\subsection{Data Collection and Analysis}

A two-part questionnaire was conceived. In the first section, the eight constructs presented in the research model were measured and adopted by using 33 items (see Table 2). The eight mechanisms have been classified as (1) Behavioral Intent, (2) Initial Trust, (3) Performance Expectation, (4) Personal Propensity, (5) Structural Assurance, (6) Task Features, (7) Technology Fit, and (8) Technological Features. Various items were measured against each construct. There was a 5-point Likert self - report scale to quantify the constructs. The Likert scale comprised of 5 answers from "strongly disagree" (1) to "strongly agree" (5). Part two of the questionnaire included the respondents' demographic information. It gathers fundamental information on the respondent's attributes for example gender, age, and work experience (year).

We piloted the questionnaire to improve its quality before the actual survey. The key aim of the pilot test was to empirically test the instrument's reliability by checking that all observed variables are accurate and reliable (Hair, Black, Babin \& Anderson, 2010). Reliability was tested for every construct based on the alpha of Cronbach for which the threshold was 0.7 (Hair et al., 2010). 35 IT professionals responded in the pilot study. On the basis of the Cronbach Alpha classification, the reliability ranged from 0.731 to 0.901 . The authors found that the alpha values from Cronbach reached 0.7 for all variables. Thus, the instrument is valid dan reliable for the actual survey. The questionnaire was reviewed to be accurate and functional after the correct reliability was verified for all measured constructs.

Using a cross sectional survey, empirical data were collected. Two hundred IT professionals from Information Management departments' government agencies were selected randomly. Having the experience, having heard, and the practice of ICT for daily tasks as well as BDA were acceptable for all IT professionals involved. All respondents have been notified of the research and all of them are volunteers and have been assured that their answers are kept confidential, that their confidentiality is maintained and that their responses are used only for the research purposes. Respondents participated in the survey in 15-20 minutes. Given the information of the BDA respondents, a total of 200 questionnaires form were obtained and screened. Fourteen insufficient answers were subsequently discarded leaving 186 valid structured data review questionnaires. 


\begin{tabular}{|l|c|l|}
\hline \multicolumn{1}{|c|}{ Variables } & Number of Items & \multicolumn{1}{c|}{ Reference } \\
\hline Behavioral Intention & 5 & Kim, Ferrin and Rao (2009) \\
\hline Initial Trust & 4 & Kim et al. (2009) \\
\hline Performance Expectation & 4 & Zhou et al. (2010) \\
\hline Personal Propensity & 4 & Mayer and Davis (1999) \\
\hline Structural Assurances & 4 & Cheskin (1999) \\
\hline Task Features & 4 & Zhou et al. (2010) \\
\hline Task-Technology Fit & 4 & Zhou et al. (2010) \\
\hline Technological Features & 4 & Zhou et al. (2010) \\
\hline Demographic & 3 & - \\
\hline
\end{tabular}

Table 2. Research Constructs

\subsection{Data Analysis}

The Partial Least Square Modeling of Structural Equations is one of the best software for verifying structured data on structural equations modeling (SEM). In the earliest phases of theory construction, if not yet complete the theoretical model and its measurement, the PLS retrieval is particularly effective in data analyses (Hair, Black, Babin, Anderson \& Tatham, 2006). The PLS model examines besides identifies (1) the measurement model and (2) the conceptual design for its reliability and validity. PLS regression was employed in this research to analyse and confirm the envisaged model and the relationship between hypothesized structures. The 186 samples were 128, that is $68.8 \%$ were males and $31.2 \%$ were females. There were 70 respondents in the first $21-29$-years range, i.e., $37.6 \%$ per cent of the sample and the second 30-39-years group had 60 respondents, i.e. 32.3\% of the sample. Respondents from the $40-49$-years group constituted 53 or $28.5 \%$ of the sample and 3 or $1.6 \%$ of the sample are 50 years old and older.

The following clusters of working experience were considered. In the group of government departments, 62 respondents or $33.3 \%$ had 6 - 10 years of experience. There were 38 participants with 6-10 years' experience. It resulted in a total of 38 , i.e. $20.4 \%$, followed by 36 respondents, 1 to 5 years of experience in jobs each. $7.5 \%$ or 14 of those who replied had working experience for 21 to 25 years, while $6.5 \%(n=12)$ had been working for 26 to 30 years. Finally, $1.1 \%$ or 2 respondents had job experience of more than 30 years.

\subsubsection{Validity and Reliability Of The Measurement Model}

Convergence validity (CV) and Internal dependability (ID) analysis as well as and discriminatory validity (DV) were performed in the model of measurement, while composite reliability (CR) and Cronbach's alpha (CA) values across all variables were measured for internal reliability. The CV measured the average extracted variance (AVE). Therefore, 3 most prevalent assessment indicators were chosen, namely AVE, CA and CR as proposed by (Fornell \& Larcker, 1981). Table 2 presents the item loading set, CA, AVE and CR results.

The approximate loads ranging from 0.763 to 0.976 in Table 3 are therefore more elevated than the acceptable level (Hair et al., 2010). The reliability of the structure stipulates how reliable a system is evaluated by its dimensions and evaluated using CA and CR. The alpha Cronbach value obtained from the TF values of 0.889 to the IT values of 0.958 and CR from 0.923 for the EP to the IT values of 0.970 . All constructs surpassed the suggested cut-off of 0.7 for both measures, which suggests an extremely good internal reliability, with Fornell \& Larcker (1981) and supported by Hair et al. (2010). As displayed in Table 3, the estimated latent construct factor loading was incredibly relevant and reaching from 0.726 to $0.9676(\mathrm{p}<.05)$. The AVE range for each construct ranged from 0.751 (PE) to 0.889 (IT), with a CV indication above 0.5 as suggested in Fornell and Larcker, (1981) which showed that there was no problem with construction cross loading.

The normal distribution of the AVE of all latent structures has been matched. to its interconstructive correlation to evaluate the DV. In order to have a successful DV (Fornell \& Larcker, 1981), the square root for the AVE of a 
building should exceed its correlations with other constructions. Moreover, Henseler (2017) suggested that diagonal values are higher in columns and rows than off-diagonal values. As can be seen in Table 3, each building had an AVE square root that surpassed interconstructive correlations (shown diagonally with bold values) and thus showed an adequate DV level.

\begin{tabular}{|l|c|c|c|c|c|}
\hline \multicolumn{1}{|c|}{ Variables } & $\begin{array}{c}\text { Number } \\
\text { of Items }\end{array}$ & Alpha value $\alpha$ & $\begin{array}{c}\text { Average Variance } \\
\text { Extracted (AVE) }\end{array}$ & Item loading & $\begin{array}{c}\text { Composite Reliability } \\
\text { (CR) }\end{array}$ \\
\hline Behavioral Intention & 5 & 0.945 & 0.821 & $0.851-0.938$ & 0.958 \\
\hline Initial Trust & 4 & 0.958 & 0.889 & $0.882-0.976$ & 0.970 \\
\hline $\begin{array}{l}\text { Performance } \\
\text { Expectation }\end{array}$ & 4 & 0.889 & 0.751 & $0.763-0.925$ & 0.923 \\
\hline Personal Propensity & 4 & 0.933 & 0.837 & $0.726-0.972$ & 0.953 \\
\hline Structural Assurances & 4 & 0.953 & 0.876 & $0.910-0.955$ & 0.966 \\
\hline Task Features & 4 & 0.900 & 0.762 & $0.850-0.889$ & 0.928 \\
\hline Task-Technology Fit & 4 & 0.908 & 0.783 & $0.803-0.938$ & 0.935 \\
\hline Technological Features & 4 & 0.945 & 0.859 & $0.891-0.957$ & 0.961 \\
\hline
\end{tabular}

Table 3. Construct Reliability, Validity and Loadings Result

\begin{tabular}{|c|c|c|c|c|c|c|c|c|}
\hline & 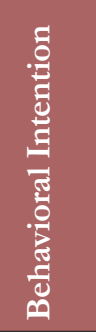 & 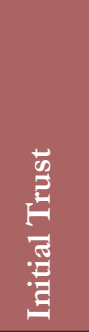 & 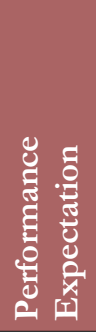 & 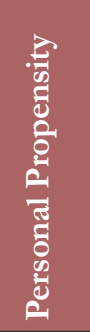 & 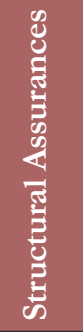 & 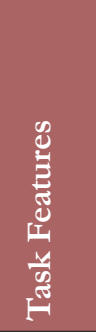 & 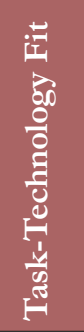 & 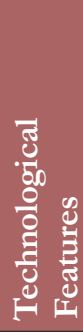 \\
\hline Behavioral Intention & 0.90 & & & & & & & \\
\hline Initial Trust & 0.240 & 0.94 & & & & & & \\
\hline Performance Expectation & 0.461 & 0.302 & 0.86 & & & & & \\
\hline Personal Propensity & 0.354 & 0.392 & 0.297 & 0.91 & & & & \\
\hline Structural Assurances & 0.473 & 0.282 & 0.435 & 0.269 & 0.93 & & & \\
\hline Task Features & 0.320 & 0.253 & 0.345 & 0.417 & 0.380 & 0.87 & & \\
\hline Task-Technology Fit & 0.438 & 0.266 & 0.399 & 0.256 & 0.404 & 0.434 & 0.88 & \\
\hline Technological Features & 0.599 & 0.556 & 0.491 & 0.511 & 0.510 & 0.437 & 0.528 & 0.92 \\
\hline
\end{tabular}

Table 4. Discriminant Validity (Fornell-Larcker's test)

\subsubsection{Statistical Analysis and Hypotheses Testing}

Path ( $\beta$ ) and T-statistics were checked for relations in dependent variables and independent variables. With PLS regression, we have found that six assumptions are significant in estimating the path relationships of each research pair between all seven paths. The bootstrapping was done to check the value of path coefficients in the internal model (number of iterations: 499). Figure 2 displays each relationship's route coefficient with the corresponding p-value. Greater t-values that 1.96 at 0.05 point is significant. Regarding UTAUT models, performance expectation (PE) was significantly positive for the BDA implementation of behavioral intent (BI) $(\beta=0.325, \mathrm{p}<0.05)$. Hypotheses 7 has therefore been supported. Findings on initial trust (IT) were also significantly positive for personal prosperity to trust (PPT) $(\beta=0.341, \mathrm{p}<0.05)$ and structural assurances (SA) $(\beta=0.191$ $\mathrm{p}<0.05)$ of the IT Model, thereby supporting hypotheses 1 and 2 . TTF Model variables, technological feature (TF) $(\beta=0.419$, $\mathrm{p}<0.05)$ and task feature $(\mathrm{Tf})(\beta=0.251, \mathrm{p}<0.05)$, both of which were important antecedents for the task-fit technology (TTF), were supported. Last but not least, TTF was a significant BDA BI determinant $(\beta=0.291, \mathrm{p}<0.05)$, supporting 
Hypothesis 6. However BI BDA was not affected by IT in government agencies as $(\beta=0.065, \mathrm{p}=0.263)$, hence Hypotheses 3 was rejected. All analyses are as illustrated in Table 5 and Figure 2.

\begin{tabular}{|l|c|c|c|c|c|}
\hline & $\begin{array}{c}\text { Original } \\
\text { Sample } \\
(\mathbf{O})\end{array}$ & $\begin{array}{c}\text { Sample } \\
\text { Mean } \\
(\mathbf{M})\end{array}$ & $\begin{array}{c}\text { Standard } \\
\text { Deviation } \\
\text { (STDEV) }\end{array}$ & $\begin{array}{c}\text { T Statistics } \\
(\mid \mathbf{O} / \text { STDEV } \mid)\end{array}$ & P Values \\
\hline Initial Trust $\rightarrow$ Behavioral Intention & 0.065 & 0.072 & 0.058 & 1.120 & $\mathbf{0 . 2 6 3}$ \\
\hline Performance Expectation $\rightarrow$ Behavioral Intention & 0.325 & 0.326 & 0.078 & 4.138 & 0.000 \\
\hline Personal Propensity $\rightarrow$ Initial Trust & 0.341 & 0.345 & 0.054 & 6.349 & 0.000 \\
\hline Structural Assurances $\rightarrow$ Initial Trust & 0.191 & 0.194 & 0.071 & 2.687 & 0.007 \\
\hline Task Features $\rightarrow$ Task-Technology Fit & 0.251 & 0.254 & 0.060 & 4.203 & 0.000 \\
\hline Task-Technology Fit $\rightarrow$ Behavioral Intention & 0.291 & 0.288 & 0.071 & 4.077 & 0.000 \\
\hline Technological Features $\rightarrow$ Task-Technology Fit & 0.419 & 0.419 & 0.065 & 6.414 & 0.000 \\
\hline
\end{tabular}

Table 5. Significant Specific Indirect Effects

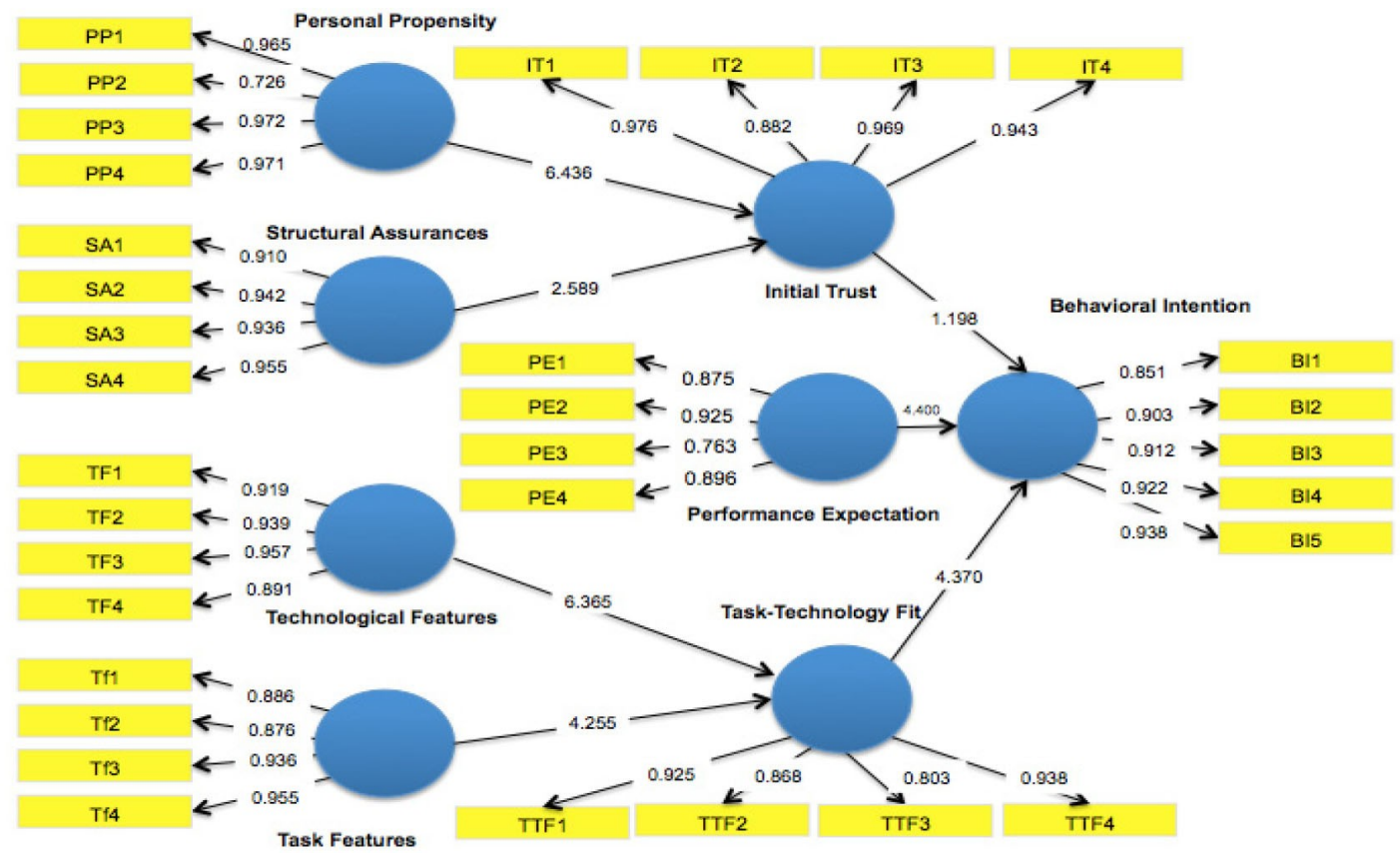

Figure 2. Research Model (Path Coefficients and P-Values)

\section{Discussion}

The findings of the study show two key determinant factors of behavioral intention to use BDA in Malaysian government agencies. The assumption that the technology is going to yield decent results raises the performance expectancy, as seen in past studies (Cabrera-Sánchez \& Villarejo-Ramos, 2019; Brünink, 2016; Chao, 2019; Queiroz, \& Farias, 2019) who found that expected results have positive and significant repercussions on BDA adoption. This indicates perception of, as has been shown in previous studies, the implementation of BDA (better decision making, competitiveness, improve services, strategic planning, new innovation in services etc.) will produce successful results if adoption rises (Yu, 2012). The respondents of the study expect BD to assist in advancing public demands for government services. They develop predictive models for innovative products and services by 
segmenting key features in service or product from the old and new testaments and by shaping the correlation between these characteristics and their business performance.

As previous studies show, technology task fit (TTF) has important consequences for the decision to use BDA (Bozan, Parker, \& Davey, 2016). The current study also analyzed TTF, with positive results on BDA adoption behavioral plans, showing that system characteristics should be compliant with the specific task of the user to effectively take up a BDA program. Furthermore, the findings which support previous studies (e.g. Shahbaz et al., 2019; Wang \& Lin, 2019; Khidzir, Diyana, Ghani, Guan \& Ismail, 2017) prove that the task and the technological features influence the compatibility of the TTF, which decides the users' intention to implement BDA. The IT professionals in Malaysian government agencies intend to plan BDA because they anticipate that BDA technology fit is capable of integrating statistics, spatial analysis, semantics, digital learning and visualisation. Similarly, in order to make correlations and concrete observations, technology fit is required to evaluate models, compare various government data types and sources.

In view of these aims, this study highlighted effective outcomes and meaning for the practical implementation of the BDA frameworks and empirical directions (for future studies). This research focused on trust, because it was found to be of great concern to system users. However, trust does not affect the behavioral intention of implementing BD in government agencies, therefore it contradicts and is not consistent with previous studies (eg. Shahbaz et al. 2019; Queiroz \& Pereira, 2019; Alalwan, Dwivedi \& Rana, 2017). It could be clarified that this discrepancy is due to the difficulty of the government agencies in Malaysia and its departments to protect the data privacy of the public. Hence, the agencies concerned must identify specific boundaries for the use of personal information. Moreover, when government agencies collect or manage public data, it is very challenging to comply with the legislation and other laws, which leads to doubt in the trust of BD. As MAMPU (2016) and Schneider, Handali and vom Brocke (2017) clearly mentioned, trusting data generation systems of public entities like Twitter and Facebook is difficult, as they have many machine-run undead accounts. Trust can be based on policy or integrity that can be accomplished by gathering, planning, processing, storing and communicating data. Furthermore, the findings for initial trust are important because it can be a potential barrier in the execution of $\mathrm{BDA}$ is underlined in the current study. The trust variable will act as a base for further studies and to gain deeper understanding of BDA study deployment.

Also, perhaps, the notion of 'trust' in BDA in government agencies in Malaysia is beyond data accuracy and security. Since trust is something intangible, it is difficult for IT professionals to focus on trust and believe that it will become a less relevant factor in value proposition of data and analytics. Thus, it is something unmanageable that will make them move forward with less confidence, affects their decision making and their customer relationships. This finding shows that more focus on the determinants of initial trust in $\mathrm{BD}$ and other technology implementation in government agencies is necessary.

The research has also shown a detrimental effect of technological features and task features on the technology task fit in government agencies. We can therefore say that the findings correspond to all hypotheses of Klopping and McKinney (2004) who used a hybrid approach that merged TTF and TA models to test e-commerce adoption (Klopping \& McKinney, 2004). The use of mobile banking was studied by Zhou et al. (2010) utilizing an adaptive TTF paradigm and the common philosophy of application adoption and usage (Zhou et al., 2010). The characteristics of BDA are advanced analytics that include complicated functions with features such as estimation methods, data mining and, if any, high-power analytics systems. Thus, this feature can directly support TTF in government agencies as the Malaysian government is serious about investing in technology facilities.

To secure the infrastructure and the way it provides services, a personal trend to trust BD providers and products is necessary. The key objective is to ensure the confidentiality, completeness, and quality of BD protection. BD collected in the cloud from a number of sources including the IoT (Internet of Things) has a number of personal views on physical and logical security. Cloud storage should be protected because the user information risks insider attacks, cyber fraud and unsafe access. Personal confidence can therefore affect confidence in BDA management.

Structural assurances are collected and processed in the increased volume of data produced, which must be relying on the source and methods to collect them over the entire life cycle. Trust considerations about collection, 
organisation, access and analysis of data are also expressed (MAMPU, 2016). BD needs to examine the structure of authenticity and credibility when considering a professional IT's perspective of the trust in large data, whether to store, socialize, buy, sell or transact information, as it can be gathered from profitable commercial organizations, which are business oriented platforms, and to check the validity of and legitimacy of the data gathered. Personal inclination of BDA can affect confidence, reputation and communication of data through collection, supply, data calculation and storage.

This study found that IT professionals are still aware that there is an inclination for using BDA technology in their everyday tasks including decision making, planning, identifying problems and needs of the community, and this tendency is well established. Therefore, the tendency to believe is in the early belief category.

In addition, BDA provides the ability to process information securely and reduce operational risks and labor shortages. Individuals do not risk making decisions and the work processes become more efficient and structured. Therefore, IT professionals may recognize that structural assurance affects their initial trust. Computer processing power is required to understand and view patterns in the data to assist in decision-making and problem solving.

\section{Conclusion}

This work examined the factors influencing the propensity of government agencies to use the BDA by using TTF, UTAUT, and initial ITM. Based on the findings, it can be understood that BDA is starting to be utilized by the respondents, and this trend is favorable. The personal willingness to trust is therefore successful. Moreover, BDA provides safe access to data and reduces operating risks and minimizes decision errors. Individuals are also not at risk in their decision making, planning and predicting.

In most previous research, the advantages, consequences and opportunities for BDA were only highlighted because $\mathrm{BDA}$ is at the early adoption and a relatively new subject. Several scholars studied BDA and the latest studies focused on a certain viewpoint or simply highlighted TAM, UTAUT, TFF, and ITM theory separately. This is the first BDA study to propose a model combining UTAUT, TTF and ITM theories as a predictor probably of comport mental intentions to use BDA. Therefore, convergence and application of all these BDA adoption ideas add new Insights into emerging literature. This study's model is helpful and promotes a theory for further BDA research. By utilizing the model, existing public agencies can know their own BDA capability, centered around activities with specifically tailored outcomes, organization dynamics, resources, skills and potential services. Government agencies can identify, within their own organization, the most common inhibitors to constructing and implementing an effective BDA and plan to mitigate these accordingly.

The study has also made various practical contributions. The findings suggest significant recommendations and consequences for $\mathrm{BDA}$ systems practitioners and application developers, which could coincide with the successful implementation of BDA systems. Connecting BDA system functions and technology features to the necessary tasks is critical. It is the same for system performance expectancy. Such strategy will yield more effective outcomes for practitioners when implementing BDA systems. This research gives practitioners an initial way to incorporate and endorse BDA activities in their organization to make the most of the advantages of revolutionary technology, particularly within public agencies.

The need to control government data and activities in real time also makes the task features fit into the task technology. With BDA, policy programs can be enforced and funded. Therefore, task-technology adaptation is effective for the behavior of the users. Finally, the limited number of skilled IT practitioners with required BDA and IT skills has brought about the attractiveness of BDA to facilitate analysis by reducing workforce costs and automating the processes. Despite the time and skills of BD using analytics, success expectations have had a positive influence on the conduct of users

\section{Declaration of Conflicting Interests}

The authors declared no potential conflicts of interest with respect to the research, authorship, and/or publication of this article. 


\section{Funding}

The authors received financial support for the research, authorship, and/or publication of this article by MOHE under the Fundamental Research Grant Scheme (FRGS) with project code: 600-IRMI/FRGS 5/3 (079/2019)

\section{References}

Abbasi, A., Sarker, S., \& Chiang, R.H. (2016). Big Data Research in Information Systems: Toward an Inclusive Research Agenda. Journal of the Association for Information Systems, 17(2), 3. https://doi.org/10.17705/1jais.00423 Available at: https://aisel.aisnet.org/jais/vol17/iss $2 / 3$

Abdullah Sani, M.K.J.B., Zaini, M.K.Z.B. , Sahid, N.Z.B, Noordin, S.A., \& Binti Baba, J. (2019). An Agile Governance of Big Data Analytics (BDA) Capabilities and Strategic Alignment to Support Malaysian Public Sector Performance: Concept Paper. Proceeding Paper, 34th International-Business Information Management Association (IBIMA) (10538-10547). Madrid, Spain.

Al-Shaikhli, H.I. (2019). Approximate Algorithms for Regulatory Motif Discovery in DNA. (2019). Dissertations, 3454. https://scholarworks.wmich.edu/dissertations/3454

Alabdallat, W.I.M. (2020). Toward a mandatory public e-services in Jordan. Cogent Business \& Management, 7(1), 1727620 .

Alalwan, A.A., Dwivedi, Y.K., \& Rana, N.P. (2017). Factors influencing adoption of mobile banking by Jordanian bank customers: Extending UTAUT2 with trust. International Journal of Information Management, 37(3), 99-110.

Alarcon, G.M., Lyons, J.B., \& Christensen, J.C. (2016). The effect of propensity to trust and familiarity on perceptions of trustworthiness over time. Personality and Individual Differences, 94, 309-315.

https://doi.org/10.1016/j.paid.2016.01.031

Alcácer, V., \& Cruz-Machado, V. (2019). Scanning the Industry 4.0: A Literature Review on Technologies for Manufacturing Systems. Engineering Science and Technology, an International Journal, 22(3), 899-919.

Ali, R.H.R.M., Mohamad, R., \& Sudin, S. (2016, August). A proposed framework of big data readiness in public sectors. In AIP Conference Proceedings (Vol. 1761, No. 1, p. 020089). AIP Publishing LLC..

Bahari, B. (2016). Malaysia on Track to Become Southeast Asian Hub on Big Data \& Analytics. New Straits Times, 19 Sept. 2018. Available at: http://www.nst.com.my/news/2016/09/174270/malaysia-track-become-southeast-asian-hub-bigdata-analytics

Ballantyne, A., \& Stewart, C. (2019). Big Data and Public-Private Partnerships in Healthcare and Research. Asian Bioetbics Review, 11(3), 315-326. https://doi.org/10.1007/s41649-019-00100-7

Behl, A., Dutta, P., Lessmann, S., Dwivedi, Y.K., \& Kar, S. (2019). A conceptual framework for the adoption of big data analytics by e-commerce startups: a case-based approach. Information Systems and e-Business Management, Springer, 17(2), 285-318.

Bello-Orgaz, G., Jung, J.J., \& Camacho, D. (2016). Social big data: recent achievements and new challenges. Information Fusion, 28, 45-59. https://doi.org/10.1016/j.inffus.2015.08.005

Bere, A. (2018). Applying an Extended Task-Technology Fit for Establishing Determinants of Mobile Learning: An Instant Messaging Initiative. Journal of Information Systems Education (JISE), 29(4), 214-228.

Bibri, S.E., \& Krogstie, J. (2017). The core enabling technologies of big data analytics and context-aware computing for smart sustainable cities: a review and synthesis. Journal of Big Data, 4, 38. https://doi.org/10.1186/s40537-017-0091-6

Bozan, K., Parker, K., \& Davey, B. (2016, January). A closer look at the social influence construct in the UTAUT Model: An institutional theory based approach to investigate health IT adoption patterns of the elderly. In 201649 th Hawaii International Conference on System Sciences (HICSS) (pp. 3105-3114). IEEE. 
Brünink, L.A. (2016). Cross-functional Big Data integration: Applying the UTAUT model (Master's thesis, University of Twente).

Cabrera-Sánchez, J.P., \& Villarejo-Ramos, Á.F. (2019). Fatores Que Afetam A Adoção De Análises De Big Data Em Empresas. Revista de Administração de Empresas, 59(6), 415-429. Epub January 10, 2020. https://doi.org/10.1590/s0034-759020190607

Cao, Q., \& Niu, X. (2019). Integrating context-awareness and UTAUT to explain Alipay user adoption. Int J Ind Ergon, 69, 9-13.

Capgemini Consulting (2014). BD Survey - Cracking the Data Conundrum: How Successful Companies Make Big Data Operational. https://www.capgemini.com/consulting/wp-content/uploads/sites/30/2017/07/big data pov 03-02-15.pdf

Chao, C.M. (2019) Factors Determining the Behavioral Intention to Use Mobile Learning: An Application and Extension of the UTAUT Model. Front. Psychol., 10, 1652. https://doi.org/10.3389/fpsyg.2019.01652

Chen, J., Chen, Y., Du, X., Li, C., Lu, J., Zhao, S., et al. (2013). Big data challenge: a data management perspective. Frontiers of Computer Science, 7(2), 157-164.

Cheskin Research and Studio Archetype/Sapient (1999). Ecommerce trust study. Available from: http://www.cheskin.com/p/ar.asp?mlid=7\&arid=40\&art=0\&isu=1. Accessed: August 16th, 2020.

D’Ambra, J., Wilson, C.S., \& Akter, S. (2013). Application of the task-technology fit model to structure and evaluate the adoption of e-books by academics. Journal of the American society for information science and technology, 64(1), 48-64. https://ro.uow.edu.au/commpapers/3189

Debussche, J., César, J. \& Moortel, I.D. (2019). Big Data \& Issues \& Opportunities: Discrimination. Bird\&bird. https://www.twobirds.com/en/news/articles/2019/global/big-data-and-issues-and-opportunities-discrimination

Desjardins, J. (2019). How much data is generated each day? Available at: https://www.weforum.org/agenda/2019/04/how-much-data-is-generated-each-dav-cf4bddf29f/

Domingue, J., Lasierra N., Fensel, A., van Kasteren, T., Strohbach, M., \& Thalhammer, A. (2016) Big Data Analysis. In Cavanillas J., Curry E., \& Wahlster W. (Eds.), New Horizons for a Data-Driven Economy. Springer, Cham.

Dzazali, S.B. (2019). Mining The Value In Your Data. Data Intelligence \& Analytics Conference.

Elragal, A., \& Klischewski, R. (2019). Theory-driven or process-driven prediction? Epistemological challenges of big data analytics. J Big Data 4, 19. https://doi.org/10.1186/s40537-017-0079-2

Erevelles, S., Fukawa, N., \& Swayne, L. (2016). Big data consumer analytics and the transformation of marketing. J of Bus Res, 69(2):897-904

Falahat, M., Lee, Y.-Y., Foo, Y.C., \& Chia, C.E. (2019). A model for consumer trust in e-commerce. Asian Academy of Management Journal, 24(2), 93-109. https://doi.org/10.21315/aamj2019.24.s2.7

Fornell, C., \& Larcker, D.F. (1981). Evaluating structural equation models with unobservable variables and measurement error. Journal of marketing research, 18(1), 39-50. https://doi.org/10.2307/3151312

Gao, L., \& Waechter, K.A. (2017). Examining the role of initial trust in user adoption of mobile payment services: an empirical investigation. Inf Syst Front, 19, 525-548. https://doi.org/10.1007/s10796-015-9611-0

Giest, S. (2017). Big Data for Policymaking: Fad or Fast'Track? Policy Sciences 50(3), 367-382

Gong, Z., Han, Z., Li, X., Yu, C., \& Reinhardt, J.D. (2019). Factors Influencing the Adoption of Online Health Consultation Services: The Role of Subjective Norm, Trust, Perceived Benefit, and Offline Habit. Front. Public Health, 7, 286. https://doi.org/10.3389/fpubh.2019.00286

Goodhue, D.L., \& Thompson, R.L. (1995). Task-technology fit and individual performance. MIS quarterly, 19(2), 213-236. https://doi.org/10.2307/249689 
Günther, W.A., Rezazade, M.H.M, Huysman, M., \& Feldberg, F. (2017). Debating big data: A literature review on realizing value from big data. Journal of Strategic Information Systems, 26(3), 191-209.

https://doi.org/10.1016/j.jsis.2017.07.003

Hair, J.F., Black, W.C., Babin, B.J., Anderson, R.E., \& Tatham, R.L. (2006). Multivariate data analysis (6). Upper Saddle River, NJ: Pearson Prentice Hall.

Hair, J.F., Black, W.C., Babin, B.J., \& Anderson, R.E. (2010). Multivariate Data Analysis. Seventh Edition. Upper Saddle River, New Jersey: Prentice Hall.

Hasan, M.M., Popp, J., \& Oláh, J. (2020). Current landscape and influence of big data on finance. J Big Data, 7, 21. https://doi.org/10.1186/s40537-020-00291-z

Heidari, H., Moosakhani, M., Alborzi, M., Divandari, A., \& Radfar, R. (2018). Investigating the Effective Factors on the Customers' Behavioral propensity to Use Blockchain Capabilities as financial instrument. J Mon Ec, 13(2), 195-219. http://ime.mbri.ac.ir/article-1-423-en.html

Helmi, M. (2018). Interview with Deputy Director General (ICT) Office, MAMPU, Dr. Suhazimah Binti Dzazali. Data.gov.my, Malaysia Open Data Blog, 25 May 2018. Available at: blog.data.gov.my/?p=81. Accessed 11 Sept. 2020

Henseler, J. (2017). Bridging Design and Behavioral Research with Variance-based Structural Equation Modelling. J Adv, 46(1), 178-192. https://doi.org/10.1080/00913367.2017.1281780

Hiruni, B., \& Piyavi, W. (2020). Critical Factors Affecting the Intention to Adopt Big Data Analytics in Apparel Sector, Sri Lanka. International Journal of Advanced Computer Science and Applications(IJACSA), 11(6). http://dx.doi.org/10.14569/IJACSA.2020.0110620

Ingrams, A. (2019). Public Values in the Age of Big Data: A Public Information Perspective. Policy \& Internet, 128-148. https://doi.org/10.1002/poi3.193

International Telecommunication Union (2018). Big data, machine learning, consumer protection and privacy. Report Of Trust Workestream. Geneva, Switzerland. https://www.itu.int/en/ITUT/extcoop/figisymposium/Documents/FIGI SIT Techinical $\% 20$ report Big $\% 20 \mathrm{data}^{2} \% 2 \mathrm{C} \% 20 \mathrm{Machine} \% 20 \mathrm{learning} \% 2 \mathrm{C}$ $\% 20$ Consumer $\% 20$ protection $\% 20$ and $\% 20$ Privacy f.pdf

Jibril, A.B., Kwarteng, M.A., Appiah-Nimo, C., \& Pilik, M. (2019). Association rule mining approach: evaluating pre-purchase risk intentions in the online second-hand goods market. Oeconomia Copernicana, 10(4), 669-688. https://doi.org/10.24136/oc.2019.032

Kaabachi, S., Mrad, B.S., \& O'Leary, B. (2019). Consumer's initial trust formation in IOB's acceptance: The role of social influence and perceived compatibility. Int J BankMark, 37, 507-530. https://doi.org/10.1108/IJBM-12-20170270

Kennedy, H., Moss, G., Birchall, C., \& Moshonas, S. (2015). Balancing the potential and problems of digital methods through action research: Methodological reflections. Information, Communication \& Society, 18(2), $172-186$. https://doi.org/10.1080/1369118X.2014.946434

Khan, N., Yaqoob, I., Hashem, I.A.T., Inayat, Z., Mahmoud Ali, W.K., Alam, M., et al. (2014). Big data: survey, technologies, opportunities, and challenges. Scientific World Journal, 712826. https://doi.org/10.1155/2014/712826

Khidzir, N.Z., Diyana, W.S., Ghani, W.A., Guan, T.T., \& Ismail, M. (2017, September). Task-technology fit for textile cyberpreneur's intention to adopt cloud-based M-retail application. In 20174 th International Conference on Electrical Engineering, Computer Science and Informatics (EECSI) (pp. 1-6). IEEE. https://doi.org/10.1109/EECSI.2017.8239125

Khidzir, N.Z., Ghani, W.S.D.W.A., \& Guan, T.T. (2017).Cloud-Based Mobile-Retail Application for Textile Cyberpreneurs: Task-Technology Fit Perspective Analysis. In Proceedings of the International Conference on High Performance Compilation, Computing and Communications (HP3C-2017) (65-70). Association for Computing Machinery, New York, USA. https://doi.org/10.1145/3069593.3069609 
Kim, D.J., Ferrin, D.L., \& Rao, H.R. (2009). Trust and satisfaction, the two wheels for successful e-commerce transactions: a longitudinal exploration. Inf Syst Res, 20(2):237-257. https://doi.org/10.1287/isre.1080.0188

Kim, E.S., Choi, Y., \& Byun, J. (2020). Big Data Analytics in Government: Improving Decision Making for R\&D Investment in Korean SMEs. Sustainability, 12, 202. https://doi.org/10.3390/su12010202

Kim, K.K., \& Prabhakar, B. (2004). Initial Trust and the Adoption of B2C e-Commerce: The Case of Internet Banking. Data Base for Advances in Information Systems, 35(2), 50-64. https://doi.org/10.1145/1007965.1007970

Klopping, I.M., \& McKinney, E. (2004). Extending the technology acceptance model and the task-technology fit model to consumer e-commerce. Information Technology, Learning, and Performance Journal, 22(1), 35-48.

Koufaris, M. \& Hampton-Sosa, W. (2004) The development of initial trust in an online company by new customers. Information and Management, 41, 377-397. https://doi.org/10.1016/j.im.2003.08.004

KPMG (2016). Building trust in analytics. https://home.kpmg.com/xx/en/home/insights/2016/10/building-trust-inanalytics.html

Kubina, M., Varmus, M., \& Kubinova, I. (2015). Use of big data for competitive advantage of company. Procedia Economics and Finance, 26(15), 561-565. https:// doi.org/10.1016/S2212 5671(15)00955-7

Kurt, Ö.E., \& Tingöy, Ö. (2017). The acceptance and use of a virtual learning environment in higher education: an empirical study in Turkey, and the UK. Int J Educ Technol High Educ 14, 26. https://doi.org/10.1186/s41239-017-0064Z

Laney, D. (2001). 3D data management: Controlling data volume, velocity and variety. In: Meta Group. Available at: http://blogs.gartner.com/doug-lanev/files/2012/01/ad949-3D-Data-Management-Controlling-Data-Volume-Velocity-andVariety.pdf (Accessed: December 2020).

Latif, Z., Tunio, M.Z., Pathan, Z.H., Jianqiu, Z., Ximei, L., \& Sadozai, S.K. (2018). A review of policies concerning development of big data industry in Pakistan: Subtitle: Development of big data industry in Pakistan. In International Conference on Computing, Mathematics and Engineering Technologies (iCoMET) (1-5). https://doi.org/10.1109/ICOMET.2018.8346315

Laugesen, J., \& Hassanein, K. (2017). Adoption of personal health records by chronic disease patients: A research model and an empirical study. Computers in Human Behavior, 66, 256-272. https://doi.org/10.1016/j.chb.2016.09.054

Lee, C.C., Cheng, H.K., \& Cheng, H.-H. (2007). An empirical study of mobile commerce in insurance industry: Task-technology fit and individual differences. Decision Support Systems, 43(1), 95-110.

https://doi.org/10.1016/j.dss.2005.05.008

Lehrer, C., Wieneke, A., Vom Brocke, J.A.N., Jung, R., \& Seidel, S. (2018). How big data analytics enables service innovation: materiality, affordance, and the individualization of service. Journal of Management Information Systems, 35(2), 424-460. https://doi.org/10.1080/07421222.2018.1451953

Lewicki, R.J., \& Bunker, B.B. (1996). Developing and maintaining trust in working relationships. In Kramer, R.M., \& Tyler, T.R. (Eds.), Trust in organizations. Frontiers of theory and research. Thousand Oaks: Sage Publications.

Lin, W-R, Wang, Y-H, Hung, Y-M (2020). Analyzing the factors influencing adoption intention of internet banking: Applying DEMATEL-ANP-SEM approach. PLOS ONE 15(2): e0227852.

https://doi.org/10.1371/journal.pone.0227852

Löfgren, K., \& Webster, C.W.R. (2020). The value of Big Data in government: The case of 'smart cities.' Big Data \& Society. https://doi.org/10.1177/2053951720912775

Longo, J., \& McNutt, K. (2018). From Policy Analysis to Policy Analytics. Policy Analysis in Canada, 367-389. https://doi.org/10.1332/policypress/9781447334910.003.0018

Madhlangobe, W. (2018). Assessment of factors influencing intent-to-use Big data analytics in an organization: A survey study. [Doctoral dissertation]. Nova Southeastern University. NSUWorks, College of Engineering and Computing. (1054). https://nsuworks.nova.edu/gscis etd/1054 
Madsen, D.Ø., \& Stenheim, T. (2016). Big Data viewed through the lens of management fashion theory. Cogent Business \& Management, 3(1), 1165072.

Mahfuz, M.A., Khanam, L., \& Hu, W. (2016). The influence of culture on m-banking technology adoption: An integrative approaches of UTAUT2 and ITM. Portland International Conference on Management of Engineering and Technology (PICMET) (824-835). Honolulu, HI. https://doi.org/10.1109/PICMET.2016.7806814

Malaka, I., \& Brown, I., (2015). Challenges to the Organisational Adoption of Big Data Analytics: A Case Study in the South African Telecommunications Industry. In Proceedings of the Annual Research Conference on South African Institute of Computer Scientists and Information Technologists. ACM.

MAMPU (2016). Analitis Data Raya Sektor Awam (DRSA). Available at: http://www.mampu.gov.my/ms/data rava-sektorawam-drsa

MAMPU (2017). Msc Malaysia Performance Focus Area Big Data Analytics (Bda) From 2011 to 2017. Available at: https://www.data.gov.my/data/en US/dataset/msc-malaysia-performance-of-focus-area-big-data-analytics-BDA

MAMPU (2020). Government Data Optimization And Transformation Services (GDOTS). https://www.malaysia.gov.my/portal/content/30614

Maroufkhani, P., Wan Ismail, W.K., \& Ghobakhloo, M. (2020). Big data analytics adoption model for small and medium enterprises. Journal of Science and Technology Policy Management, 11(4), 483-513. https:/ /doi.org/10.1108/JSTPM-02-20200018

Mayer, R.C., \& Davis, J.H. (1999). The effect of the performance appraisal system on trust for management: A field quasi-experiment. Journal of Applied Psychology, 84(1), 123-136. https://doi.org/10.1037/0021-9010.84.1.123 Available from: https://www.researchgate.net/publication/257141424 A new propensity to trust scale and its relationship with individ ual well-being Implications for HRM policies and practices. Accessed Feb 05 ${ }^{\text {th }}, 2021$.

McCole, P., Ramsey, E., Kincaid, A., Fang, Y., \& Li, H. (2019). The role of structural assurance on previous satisfaction, trust and continuance intention: The case of online betting. Information Technology and People. https://doi.org/10.1108/ITP-08-2017-0274

McFarland, D.A., \& McFarland, H.R. (2015). Big Data and the danger of being precisely inaccurate. Big Data and Society, 2(2), 1-4.

McKnight, D.H., \& Chervany, N.L. (2006). Reflections on an initial trust-building model. In Handbook Of Trust Research (29-51). Edward Elgar Publishing. https://doi.org/10.4337/9781847202819.00008

Mikalef, P., Boura, M., Lekakos, G., \& Krogstie, J. (2019). Big data analytics and firm performance: Findings from a mixed-method approach. Journal of Business Research, 98, 261-276. https://doi.org/10.1016/j.jbusres.2019.01.044

Mikalef, P., Pappas, I.O., Krogstie, J., \& Giannakos, M. (2018). Big data analytics capabilities: A systematic literature review and research agenda. Information Systems and e-Business Management, 16(3), 547-578.

https://doi.org/10.1007/s10257-017-0362-y

Mithas, S., Tafti, A., Bardhan, I., \& Goh, J.M. (2012). Information Technology and Firm Profitability: Mechanisms and Empirical Evidence. MIS Quarterly, 36(1), 205-224. Available at: https://ssrn.com/abstract=1000732 https://doi.org/10.2307/41410414

Moore, G.C., \& Benbasat, I. (1991). Development of an Instrument to Measure the Perceptions of Adopting an Information Technology Innovation. Information Systems Research (2-3), 192-222. https://doi.org/10.1287/isre.2.3.192

Munné, R. (2016). Big Data in the Public Sector. In Cavanillas J., Curry E., \& Wahlster W. (Eds.), New Horizons for a Data-Driven Economy. Cham: Springer. https://doi.org/10.1007/978-3-319-21569-3_11

Naqvi, M.H.A., Jiang, Y., Miao, M., \& Naqvi, M.H. (2020). The effect of social influence, trust, and entertainment value on social media use: Evidence from Pakistan. Cogent Business \& Management, 7(1).

https://doi.org/10.1080/23311975.2020.1723825 
Ngampornchai, A., \& Adams, J. (2016). Students' acceptance and readiness for E-learning in Northeastern Thailand. Int J Educ Technol High Educ, 13, 34. https://doi.org/10.1186/s41239-016-0034-x

Nantais, J. (2019). Towards Data Science. https://towardsdatascience.com/@joelnantais

OECD (2018). Digital Government Review of Colombia: Towards a Citizen-Driven Public Sector. OECD Digital Government Studies. Paris: OECD Publishing. https://dx.doi.org/10.1787/9789264291867-en

Omotayo, F.O., \& Haliru, A. (2020). Perception of task-technology fit of digital library among undergraduates in selected universities in Nigeria. The Journal of Academic Librarianship, 46(1), 102097. https://doi.org/10.1016/j.acalib.2019.102097

Oliveira, T., Faria, M., Thomas, M.A., \& Popovic, A. (2014). Extending the understanding of mobile banking adoption: When UTAUT meets TTF and ITM. International Journal of Information Management, 34(5), 689-703.

Okello, D.R., \& Gilson, L. (2015). Exploring the influence of trust relationships on motivation in the health sector: a systematic review. Human resources for health, 13, 16. https://doi.org/10.1186/s12960-015-0007-5

O'Connor, Y., Andreev, P., \& O'Reilly, P. (2020). MHealth and perceived quality of care delivery: a conceptual model and validation. BMC medical informatics and decision making, 20(1), 41. https://doi.org/10.1186/s12911-020-1049-8

Oliveira, T., Faria, M., Thomas, M.A., \& Popovič, A. (2014). Extending the understanding of mobile banking adoption: When UTAUT meets TTF and ITM. International Journal of Information Management, 34(5), 689-703.

Pencheva, I., Esteve, M., \& Mikhaylov, S.J. (2020). Big Data and AI - A transformational shift for government: So, what next for research? Public Policy and Administration, 35(1), 24-44. https://doi.org/10.1177/0952076718780537

Paramasivam, S. (2016). 85\% of Malaysian Businesses Feel the Need For a Modern Data Culture - Yet 44\% Have a Limited Digital Strategy in Place. Microsoft Malaysia News Center. https://news.microsoft.com/en-my/2016/05/11/85malaysian-businesses-feel-need-modern-data culture-yet-44-limited-digital-strategy-place/\# ftn1

Queiroz, M.M., \& Farias, S.C. (2019). Intention to adopt big data in supply chain management: A Brazilian perspective. RAE-Revista de Administração de Empresas, 59(6), 389-401. https://doi.org/10.1590/S0034-759020190605

Queiroz, M.M., \& Pereira, S.C.F. (2019). Intention to adopt big data in supply chain management: A Brazilian perspective. Revista de Administração de Empresas, 59(6), 389-401.

Raguseo, E., \& Vitari, C. (2018). Investments in big data analytics and firm performance: an empirical investigation of direct and mediating effects. International Journal of Production Research, 56(15), 5206-5221, https://doi.org/10.1080/00207543.2018.1427900

Rai, R.S., \& Selnes, F. (2019). Conceptualizing task-technology fit and the effect on adoption-a case study of a digital textbook service. Inf Manag, 56, 103161.

Raja Mohd Ali, R.H., Mohamad, R., \& Sudin, S. (2016). A proposed framework of big data readiness in public sectors. In: International Conference on Applied Science and Technology 2016 (ICAST'16), 11-13, April 2016, Kedah, Malaysia.

Rialti, R., \& Zollo, L., \& Ferraris, A., \& Alon, I. (2019). Big data analytics capabilities and performance: Evidence from a moderated multi-mediation model. Technological Forecasting and Social Change, 149.

Said, G.R.E. (2015). Understanding knowledge management system antecedents of performance impact: Extending the task-technology fit model with intention to share knowledge construct. Future Business Journal, 1(1-2), 75-87. https://doi.org/10.1016/j.fbj.2015.11.003

Sam, K.M, \& Chatwin, C.R. (2019). ChatwinUnderstanding adoption of big data analytics in China: from organizational users perspective Paper. presented at the IEEE International Conference on Industrial Engineering and Engineering Management, 507-510.

Sbaffi L, \& Rowley J. (2018). Trust and Credibility in Web-Based Health Information: A Review and Agenda for Future Research. J Med Internet Res, 19(6), e218. https://doi.org/10.2196/jmir.7579 
Schindler, L.A., Burkholder, G.J., Morad, O.A., \& Marsh, C. (2017). Computer-based technology and student engagement: a critical review of the literature. Int J Educ Technol High Educ, 14, 25.

https://doi.org/10.1186/s41239-017-0063-0

Schintler, L.A., \& Kulkarni, R. (2014). Big Data for Policy Analysis: The Good, the Bad, and the Ugly. Review of Policy Research, 31(4), 343-348. https://doi.org/10.1111/ropr.12079

Schneider, J., Handali, J.P., \& vom Brocke, J. (2018). Increasing trust in (big) data analytics. In International Conference on Advanced Information Systems Engineering (pp. 70-84). Springer, Cham. https://doi.org/10.1007/978-3-319-92898-2_6

Schneider, J., Handali, J.P., \& vom Brocke, J. (2018). Increasing Trust in (Big) Data Analytics. Paper presented at the 30th International Conference on Advanced Information Systems Engineering (CAiSE) (VHB_3: C), Tallin, Estonia. https://doi.org/10.1007/978-3-319-92898-2_6

Schüll, A. \& Maslan, N. (2018). On the adoption of big data analytics: interdependencies of contextual factors. Proceedings of the 20th International Conference on Enterprise Information Systems (ICEIS) (1, 425-431). https://doi.org/10.5220/0006759904250431

Shahbaz, M., Gao, C., Zhai, L., Shahzad, F., \& Hu, Y. (2019b). Investigating the adoption of big data analytics in healthcare: the moderating role of resistance to change. J Big Data, 6, 6. https://doi.org/10.1186/s40537-019-0170-y

Sivarajah, U., Kamal, M.M., Irani, Z., \& Weerakkody, V. (2017). Critical analysis of Big Data challenges and analytical methods. Journal of Business Research, 70, 263-286. https://doi.org/10.1016/j.jbusres.2016.08.001

Smithson, M. (2018) Trusted Autonomy Under Uncertainty. In Abbass, H., Scholz, J., \& Reid, D. (Eds), Foundations of Trusted Autonomy. Studies in Systems, Decision and Control (117). Cham: Springer. https://doi.org/10.1007/978-3-31964816-3_10

Spies R., Grobbelaar S., \& Botha A. (2020). A Scoping Review of the Application of the Task-Technology Fit Theory. In Hattingh M., Matthee, M., Smuts, H., Pappas, I., Dwivedi, Y., \& Mäntymäki M. (Eds.), Responsible Design, Implementation and Use of Information and Communication Technology. I3E 2020. Lecture Notes in Computer Science, 12066. Cham: Springer.

Stedman, C. (2017). Eyeing the future with predictive analytics can pay dividends now. Available at: http://searchbusinessa nalytics.techtarget.com/ehandbook/Predictive-data-analytics-advances-businesses-ahead-of-the-game

Talwar, S., Dhir, A., Kaur, P., \& Mäntymäki, M. (2020). Why do people purchase from online travel agencies (OTAs)? A consumption values perspective. International Journal of Hospitality Management, 88 (2020), 102534. https://doi.org/10.1016/j.ijhm.2020.102534

Tam, C., \& Oliveira, T. (2016). Understanding the impact of $\mathrm{m}$-banking on individual performance: DeLone \& McLean and T'TF perspective. Computers in Human Behavior, 61, 233-244. https://doi.org/10.1016/j.chb.2016.03.016

The Multimedia Development Corporation (MDeC) (2016). MDeC To Make Malaysia Regional Hub For Big Data Analytics. http://smeam.gomalaysia.com.my/en/news/27010

The World in 2050 (2019). The Digital Revolution and Sustainable Development: Opportunities and Challenges. Report prepared by The World in 2050 initiative. International Institute for Applied Systems Analysis (ILASA), Laxenburg, Austria. http://www.twi2050.org/

UNESCO Institute for Statistics (UIS) (2016). The Data Revolution in Education. Montreal: UNESCO Institute for Statistics. http://uis.unesco.org/sites/default/files/documents/the-data-revolution-in education-2017-en.pdf https://doi.org/10.15220/978-92-9189-213-6-en

Uddin, M., Alam, M.S., Mamun, A.A., Khan, T.U.Z., \& Akter, A. (2020). A study of the adoption and implementation of enterprise resource planning (ERP): Identification of moderators and mediator. Journal of Open Innovation: Technology, Market, and Complexity, 6.

Venkatesh, V., \& Davis, F. D. (2000). A theoretical extension of the technology acceptance model: Four longitudinal field studies. Management science, 46(2), 186-204. 
Venkatesh, V., Morris, M., Davis, G., \& Davis, F. (2003). User Acceptance of Information Technology: Toward a Unified View. MIS Quarterly, 27(3), 425-478. https://doi.org/10.2307/30036540

Vitari, C., \& Raguseo, E. (2019). Big data analytics business value and firm performance: Linking with environmental context. Post-Print hal-02293765, HAL.

Vongjaturapat, S. (2018). Application of the Task-Technology Fit Model to Structure and Evaluation of the Adoption of Smartphones for Online Library Systems. Science \& Technology Asia, 23(1), 39-56. Available at: https://ph02.tci-thaijo.org/index.php/SciTechAsia/article/view/124831

Wang, S.L., \& Lin, H.I. Shu Lin Wang \& Hsin I Lin (2019) Integrating TTF and IDT to evaluate user intention of big data analytics in mobile cloud healthcare system. Behaviour \& Information Technology, 38(9), 974-985. https://doi.org/10.1080/0144929X.2019.1626486

Walker, R., \& Brown, I. (2019). Big data analytics adoption: A case study in a large South African telecommunications organisation. SA Journal of Information Management, 21(1), 10. https://doi.org/10.4102/sajim.v21i1.1079

Wang, L., \& Jones, R. (2017). Big Data Analytics for Network Intrusion Detection: A Survey. Internationaı Journal of Networks and Communications, 7(1), 24-31. https://doi.org/10.5923/j.ijnc.20170701.03

Wang, S.J., \& Moriarty, P. (2018). Barriers to the Implementation of Big Data. In Big Data forUrban Sustainability, 65-80. Cham, Springer.

Wang, S.L., \& Lin, H.I. (2019). Integrating TTF and IDT to evaluate user intention of big data analytics in mobile cloud healthcare system. Behaviour \& Information Technology, 38(9), 974-985.

Woolley, J.P. (2019). Trust and Justice in Big Data Analytics: Bringing the Philosophical Literature on Trust to Bear on the Ethics of Consent. Philosophy \& Technology, 32(1), 111-134. https://doi.org/10.1007/s13347-017-0288-9

World Bank (Global Knowledge and Research Hub in Malaysia) (2017). The Malaysia Development Experience Series: Open Data Readiness Assessment. World Bank Group. Available at http://documents1.worldbank.org/curated/en/529011495523087262/pdf/115192-WP Public-Malaysia-DevelopmentExperience-Series.Pdf

Wu, B., \& Chen, X. (2017). Continuance intention to use MOOCs: Integrating the technology acceptance model (TAM) and task technology fit (T'TF) model. Computers in Human Behavior, 67, 221-232. https://doi.org/10.1016/j.chb.2016.10.028

Yang, H.H., Feng, L., \& MacLeod, J. (2019). Understanding College Students' Acceptance of Cloud Classrooms in Flipped Instruction: Integrating UTAUT and Connected Classroom Climate. Journal of Educational Computing Research, 56(8), 1258-1276. https://doi.org/10.1177/0735633117746084

Yoo, S.K., \& Kim, B.Y. (2019). The effective factors of cloud computing adoption success in organization, Journal of Asia Finance, Economics and Business, 6(1), 215-227. https://doi.org/10.13106/jafeb.2019.vol6.no1.217

Yu, C.S. (2012). Factors affecting individuals to adopt mobile banking: Empirical evidence from the UTAUT model. Journal of Electronic Commerce Research, 13(2), 104-121.

Yu, S., \& Lee, J. (2019). The effects of consumers' perceived values on intention to purchase upcycled products. Sustainability, 11, 1034. https://doi.org/10.3390/su11041034

Yunus, Y.B. (2018). Harnessing Data Science For Data Driven Public Service Delivery. 6 th Malaysia Statistics Conference, Sasana Kijang, Bank Negara Malaysia.

Zhou, L. (2013). An empirical examination of continuance intention of mobile payment services. Decision Support Systems, 54, 1085-1091. https://doi.org/10.1016/j.dss.2012.10.034

Zhou, T., Lu, Y., \& Wang, B. (2010). Integrating TTF and UTAUT to explain mobile banking user adoption. Computers in human behaviour, 26(4), 760-767. https://doi.org/10.1016/j.chb.2010.01.013 
Zhuang, Y.T., Wu, F., Chen, C., \& Pan, Y.H. (2017). Challenges and opportunities: from big data to knowledge in AI 2.0. Frontiers Inf Technol Electronic Eng, 18, 3-14. https://doi.org/10.1631/FITEE.1601883

Journal of Industrial Engineering and Management, 2021 (www.jiem.org)

\section{(c) (1) (8)}

Article's contents are provided on an Attribution-Non Commercial 4.0 Creative commons International License. Readers are allowed to copy, distribute and communicate article's contents, provided the author's and Journal of Industrial Engineering and Management's names are included. It must not be used for commercial purposes. To see the complete license contents, please visit https://creativecommons.org/licenses/by-nc/4.0/. 